\title{
Rodrigo Cánovas
}

\section{Voces judaicas en México y en Chile. Nuevos acogimientos, antiguas huerfanías}

Quiero referirme a relatos muy recientes escritos por mexicanos y chilenos en torno al origen y al porvenir judío en estas latitudes. He elegido voces de una tercera generación de inmigrantes que escriben en el inicio de este siglo XXI, que señalan nuevas rupturas y continuidades con esas jaulas invisibles que son la familia, el país y la noción de "pueblo judío".

De los judíos en México, sabemos que constituyen una comunidad de comunidades, cuyos antecedentes remiten a los judíos árabes provenientes de Damasco (los shamis) y de Alepo (los alebis); los sefarditas de Macedonia e Istambul; y los ashkenazis del antiguo Palio de Residencia en tiempos del zar, de los shtels de las ciudades europeas y del corazón de las capitales contaminadas con el nazismo. Esta experiencia judía ha sido transcrita primero en yiddish y luego en español, sin dejar de lado, desde la escritura sefardí, el yudesmo. Las mujeres mexicanas se toman la palabra hacia el último tercio del siglo XX, generando una constelación de voces que incluye los relatos genealógicos de Margo Glantz, las visitaciones a la morada del Sefarad de Angelina Muñiz-Huberman, los rezos poéticos de Gloria Gervitz y las plegarias teológicas de Esther Seligson, que iluminan el cielo americano.

Sea casualidad o no, sólo recientemente es posible visualizar una esfera de relatos judíos escritos por mexicanos, generalmente los nietos hombres de los primeros inmigrantes. Nombramos aquí a Jacobo Sefamí (nacido en 1957), Ilan Stavans (nacido en 1961) y Gerardo Kleinburg (nacido en 1964), que proponen imágenes opuestas y complementarias del sujeto judío contemporáneo. Así, los retoños shamis o "apapachados" (según la expresión mexicana) de la novela Los dolientes (2004) de Sefamí tienen su contraparte en la figura del American Jew, quien corta con sus raíces judío-mexicanas en la autobiogra- 
fía On Borrowed Words (2001) de Stavans. Estas dos obras son las elegidas para su breve comentario en este trabajo.

De los judíos en Chile, a diferencia de México, no hay grandes recuentos ni textos celebratorios sobre su llegada, ya sea desde Macedonia y Salónica (en el caso sefardita), desde Ucrania y tierras sucedáneas de Europa del Este, y más adelante, de la misma Alemania nazi. Con rasgos de asimilación más marcados, sí han tenido una participación activa en el ámbito político, que continúa hasta hoy. Si alguien hubiera inquirido por las voces judías en ese confín del mundo hacia 1989, fecha de la caída de la dictadura chilena -que coincide con la caída del muro de Berlín-, no hubiera encontrado más de dos o tres relatos, escritos en un español vacilante por unos inmigrantes judíocomunistas que venían huyendo del mapa convulsionado de Europa. Y sin embargo, desde la caída de la estatua de Pinochet, he contado al menos diecisiete textos, escritos por gentes de diversas edades, que rompen un obstinado silencio para exhibir historias familiares marcadas por el daño, pero siempre sujetas a una sublimación a través del ejercicio de la memoria.

Anotemos de paso que estos discursos sobre la experiencia judía conforman una serie alterna junto a otros discursos, que exponen a la cultura chilena a nuevas sensibilidades y formas de pensar lo nacional. Testimonios indígenas bilingües, relatos históricos que resitúan a la mujer en la historia nacional y la irrupción de las voces huérfanas, que eclipsan las utopías parentales, renunciando voluntariamente a su cotutela. Volviendo a las voces judías, considero que las obras de Marjorie Agosín, Ariel Dorfman y de Alejandro Jodorowsky constituyen ejercicios artísticos de gran valía en el ámbito de la lengua española. Y en el caso de Agosín, habrá que recordar su amplia labor cultural que hermana espíritus y lenguas, que nos ha devuelto una sagrada memoria, en clave americana.

Hoy queremos alinear junto a los relatos de los mexicanos Sefamí y Stavans, dos textos chilenos muy recientes, escritos también por judíos de la tercera generación de inmigrantes, que exploran el desolado paisaje de los exilios y las errancias habitado por sujetos en tránsito. Nos referimos a Bosque quemado (2007) de Roberto Brodsky (nacido en 1957) y Poste restante (2001) de Cynthia Rimsky (nacida en 1962). Nuestro objetivo es presentar sus obras, un "estar allí" de ellas, sin recargar en demasía este paisaje literario con un lenguaje 
sociocultural que predique y concluya generalidades. Señalo esto como uno de los límites conscientes de esta lectura.

\section{La casa shami}

Pocas veces tenemos la oportunidad de entrar libremente a una casa que no es la nuestra y observar la vida cotidiana de una familia, los dimes y diretes, sus pequeñas miserias y grandezas, como si estuviéramos asistiendo a una obra de teatro. Es el caso de la novela Los dolientes, de Jacobo Sefamí, que nos abre la casa shami para que acompañemos a la familia durante los diez días de luto por el patriarca de ese hogar, don Simón Galante, hijo de judíos árabes venidos de Damasco, comerciante poco exitoso, casado también con una shami y con una prole de siete hijos, hombres ya mayores y con descendencia. Durante la lectura de esta novela nos vemos inmersos en el tiempo del luto, que interrumpe el calendario habitual, superponiendo el calendario judío, borrando de paso fechas republicanas.

En efecto, la obra se abre con la muerte de Simón ben Raquel en Ciudad de México un viernes 13 de septiembre de 1996 y concluye el 23 de septiembre; sin embargo, se nos anuncia desde el inicio que el deceso ocurre en realidad en los últimos minutos del 29 Elul 5756, en vísperas del shabat. Durante los siguientes capítulos - cada uno precedido por una regla del avelut (duelo)- asistimos a la celebración del luto, que misteriosamente coincide aquí con el Rosh Hashaná. ¿¡Qué mejor homenaje pueden hacer los hijos, algo alejados de los ritos, que volverse a contaminar con la tradición teológica, cumpliendo así el mandato de "respetar las costumbres legendarias de la comunidad" (Sefamí 2004: 57)?! Y más aún, ¿qué mejor prueba de fidelidad a la tradición religiosa damasquina que hacer oídos sordos al famoso grito libertario del cura Hidalgo, que se repite sagradamente todos los 16 de septiembre en los zócalos mexicanos, por la celebración del día de la Independencia? Pues, efectivamente, ante el luto del patriarca, una voz coral fraterna reconoce fascinada: "Ninguno de nosotros se acordó que ésa era la noche del grito de Independencia" (Sefamí 2004: 76).

Esta novela es una afectuosa y didáctica invitación para renovar un espíritu comunitario fundado en un compromiso trascendente, sin que ello implique renunciar al goce de la vida o abogar por la santidad de sus miembros. Por el contrario, se juntan aquí rezos y comidillos, 
chismes y pláticas teológicas, en un retrato de costumbres animado por medio centenar de personajes, que constantemente se están saliendo de las normas, buscando nuevos acogimientos sin renunciar al más antiguo y genuino.

Texto híbrido, serio y picaresco, que exhibe de modo risueño los códigos de comportamiento de la familia shami y las búsquedas existenciales que emprenden las nuevas generaciones - que coinciden con la del autor, nacido en 1957- para validarse como judíos. Por de pronto, existe un ansia de (re)educarlas en ritos y tradiciones; lo cual no impide que uno de los mayores goces en la lectura consista en la fricción que ocurre entre las reglas religiosas y el mundo cotidiano. Así, vemos sufrir a Saqui por no poder aliviarse de sus almorranas con un baño de tina de agua caliente, puesto que produciría placer (y eso está prohibido en el luto). Hay situaciones chistosas que exhiben la humana complejidad de ritos y costumbres. Así, el caso de Isaac Helfón, que muestra una aleación heterodoxa: su trabajo es el de rezar de casa en casa por el alma de los muertos, trabajo que ha conseguido gracias a los amigos de la comunidad para poder pagar sus deudas de juego (es un vicioso del casino y de la hípica). Ahora bien, la paidea damasquina se impone en tono semiserio con las conversaciones con los rabinos (algunos más atinados que otros) y, ya saliéndose de la fábula, con el añadido de un glosario de 160 términos que aclara las referencias religiosas judías, junto con palabras en árabe (pronunciadas por los mayores) y en hebreo, constantes en el texto, a modo de ayuda de memoria para los olvidadizos, y en el caso de los lectores gentiles, a modo de cultura general.

¿Qué aprendemos de la familia shami? ¿Qué variaciones ha sufrido de una generación a otra? Por de pronto, la autoría considera que el repaso teológico otorgará un mayor sentido a la búsqueda emprendida por los hijos de Simón Galante, para habitar con más independencia y comodidad esta casa judía y de paso la casa mexicana. Desde el andar de los hijos, podemos deducir algunos de los rasgos del antiguo orden de la familia shami: gente dedicada exclusivamente a los negocios, incluida en una red de parentesco cerrada y que respeta las tradiciones. Un código muy valorado en la novela (y defendido emocionalmente por los hijos) es la solidaridad entre parientes y cercanos, en el ámbito laboral: una ética de comportamiento. Así, el conflicto familiar más serio en vida de Don Simón es el abuso que soporta de su hermano 
mayor, de nombre León, hombre aventajado en los negocios que lo mantiene como un subordinado en su mueblería; además de no ayudarlo en una estafa causada por el esposo de su hijastra, apodado "el ratero". Existe una sanción también moral sobre este León, por cuanto no respetó el tiempo de luto de viudez para casarse nuevamente; además de hacerlo con una mujer goi inescrupulosa, que no ayuda en esta solidaridad familiar. Presentado como comidillo, la mezcla amorosa de un shami con una gentil ofrece resistencia; pero será un camino que algunos de los hijos seguirán, con ambivalentes resultados. Y aquí, la autoría no toma claramente partido.

Revisemos la hoja de ruta de estos hijos nacidos hace medio siglo, nietos de inmigrantes venidos de la región del Levante. Llama la atención, primero, que son siete hijos (cuyas edades fluctúan entre los 28 y los 40 años) y que la única mujer, Raquel, muere siendo muy niña en un trágico accidente. Jaime, el mayor, sigue la senda trazada por la casa paterna: se dedica desde muy joven a los negocios, se casa con una shami, es buen hermano y respeta las normas de la comunidad, aunque de modo pasivo. De los siguientes, se relata la salida al mundo de cuatro de ellos -Abram, Saqui, Musa y Beni. Es gente querendona de su casa, algo agobiada por los códigos familiares, que busca nuevas respuestas en el laberinto del mundo. Tres de ellos viajan a Israel y viven en un kibutz, pero ello no despeja su identidad judía; por el contrario, los confunde, e incluso en uno de ellos esa visita es fuente de una conducta evasiva a través de la droga: Musa aprende a fumar mariguana y luego seguirá en México experimentando con el peyote, acaso una alegoría del espíritu demasiado nacionalista -absorvente y mareador- mexicano.

En realidad, estos tres emprenden búsquedas erráticas que los dejan confundidos en la mitad de sus vidas. Obviamente, se quiere salir del gheto shami, de la dedicación exclusiva al comercio y también se quiere explorar amorosamente el mundo gentil, matriz alterna de sentidos. Lo cierto, sin embargo, es que son búsquedas frustradas. Si existe un afán moral en el texto, es la invitación a recoger un código trascendente que guíe nuestras vidas.

Habrá que aclarar que estos hijos siempre han sido shamis y que de modo intermitente han seguido las fiestas religiosas; por lo cual, lo que necesitan es una "ayuda de memoria". No es extraño que más que aprender por primera vez muchos rezos, los vayan recordando, y 
que desde el presente del luto empiecen ahora sí, ante la muerte del patriarca, a preguntarse por los fundamentos, a prestar atención a la explicación de los rabinos, apropiándose así de las primeras letras sagradas, alfa y beta, y descubriendo por ejemplo que la bet une el mundo de arriba con el de abajo y representa la forma de una casa abierta. Todo lo cual no quita reírse también socarronamente de la retórica de algunos santos varones, como aquel rabino argentino que entusiasmado con los juegos de palabras exclama: "ahora es importante ponerse las nuevas ropas, cambiarse de casa y habitar la casa de hazme. ¡Cambio de casa, señores, y no casa de cambio!” (Sefamí 2004: 134). La escena es celebrada por Helfón, el encargado de dirigir los rezos, quien ha perdido todo su dinero en los juegos de azar. Comprobamos que la familia shami mexicana goza de muy buen humor, lo cual le ayuda a restablecer el diálogo cada vez más problemático entre el cielo y la tierra.

\section{The Promised Land}

Ilan Stavans, tercera generación asquenazí en México, escribe una temprana autobiografía en un idioma recién aprendido, el inglés, ya instalado en Nueva York y gozando de la ciudadanía norteamericana. On Borrowed Words es un rito de pasaje autoimpuesto para poder hablar, pronunciar esas primeras palabras que no estén al alcance de una censura temida: un país, un hogar, un idioma. Es también un primer bosquejo de una Tierra Prometida, una traducción judaica del american dream y una primera renuncia a una tradición reciente, del cual no se quiere ser esclavo ("México lindo y querido", según reza el inicio de una canción popularizada por el mariachi Jorge Negrete, y que el mismo Ilan canturrea en Nueva York).

Compuesto, según el comentario del autobiógrafo, como un almanaque ("a registry of reminiscences"; Stavans 2001: 248) o como una serie de imágenes fílmicas ("a series of snapshots"; Stavans 2001: 248), el libro se da vueltas en torno a retratos familiares, viajes en busca de un centro (Cuba, Israel, España), lecturas judaicas (principalmente, en yiddish y en hebreo), imágenes del colegio hebreo y de la universidad mexicana; siendo el centro rector la ciudad de Nueva York, donde se instala a los 24 años para estudiar en el prestigioso Jewish Theological Seminary. Habiendo elegido un hogar (Manhat- 
tan), decide volverse a nombrar desde otra lengua, English, concebida como más lógica, más literaria y más útil que el idioma español.

A diferencia de sus antepasados, que salieron de modo apresurado huyendo en estampida y cayendo en lugares remotos, Ilan cruza la frontera voluntariamente, en un acto que lo redime: "I feel no need to return [...] I did not suffer [...] My emigration was carefully planned" (Stavans 2001: 22). ¿Un parto sin dolor? ¿Una nueva máscara del Yo? $¿ \mathrm{O}$ simplemente la partida del héroe y sus nupcias en un espacio sagrado, donde se revela que su lugar de nacimiento y su genealogía fueron sólo un accidente para el descubrimiento posterior de su ser (judaico)?

Stavans abandona el hogar, el país y los sueños revolucionarios latinoamericanos, reinventándose como sujeto judío en otro espacio y otra lengua: "I turned Manhattan into my true home" (Stavans 2001: 21). Condenado en el espacio familiar mexicano a una temprana orfandad, puesto que todos los desvelos se desplazan hacia un hermano esquizofrénico, pronto desarrolla también un gran desapego con la comunidad judía-mexicana, por su mentalidad de gueto, y con México mismo, por su supuesto desprecio a la palabra escrita.

New York. "Labyrinthine libraries around me, where I could get lost" (Stavans 2001: 22). Un laberinto de símbolos, una tradición viva. "A place where my Jewishness was valued" (Stavans 2001: 22). Allí Stavans recobra una visibilidad primigenia, sintiendo de paso que su mentalidad judía se puede expresar en sintonía con otras mentalidades $\mathrm{e}$, incluso, que puede desviarlas hacia su curso.

English. El ejercicio de la nueva identidad tiene un registro ineludible: el inglés. En un párrafo que opera como un manifiesto, a pocas páginas del final, Stavans se despoja del español, the father tongue. Citémoslo:

English is almost mathematical. Its rules manifest themselves in an iron fashion. This is in sharp contrast to Spanish, of course, whose Romance roots make it a free-flowing, imprecise language, with long and uncooperative words. As a language, it is somewhat undeserving of the literature it has created. This might explain why I enjoy rereading One Hundred Years of Solitude far more in English than in the original, as well as Don Quixote. For me, mastering English was, as I convinced myself, a ticket to salvation. Spanish, in spite of being the third-most-important language on the globe, after Chinese and English, is peripheral. It is a language that flourishes in the outskirts of culture, more reactive than active (Stavans 2001: 223). 
Quizás sería un error argüir en contra de las ideas expuestas en la cita. Más interesante resulta inquirir por la subjetividad que la sustenta. En realidad están diseñadas para provocar (¿García Márquez suena mejor en inglés?): contra la norma, en polémica abierta con otros discursos aceptados como verdad. Un Yo se retroalimenta de una batería de clichés para irritar a un fantasma (la cultura latinoamericana), algo que le fue semidonado y que esta escritura intercambia por un aleph condensado en una mentalidad New England, espacio de reinvención. En efecto, como en la novela familiar (freudiana), todos hemos imaginado otros lugares de nacimiento (porque quizás lo tuvimos, como Edipo, Moisés o Gabriel, que habría nacido en Macondo): "Is it possible that I should have been born in the region [New England] but mistakenly ended up elsewhere?" (Stavans 2001: 242).

La autoría queda feliz si el lector reacciona rabiosamente contra sus opiniones. Considero que la negación del idioma español (de identificarse en ese lugar, de habitar allí) está en concordancia con la negación del hogar, de la educación judía recibida en México y del país. No se los puede borrar, por supuesto y por lo mismo, el juego transgresivo se exacerba. Aunque su inglés es pobre (habrá que decirlo), su tono revela una impulsividad barroca propia de la literatura surgida en tierras del Sefarad.

Stavans es un judío políglota, que al yiddish y al español agregó más adelante el hebreo y, como paraguas, el inglés. Elige escribir su autorretrato acaso en la lengua que menos domina; pero que le asegura un territorio no minado. Se trata, en su caso, de poner al lector hispanoamericano en un pie forzado: de señalarle en otra lengua su marginalidad. Es el "ninguneo", que se proyecta hacia la casa mexicana, incapaz de haberle señalado el recto camino hacia los orígenes.

En las páginas finales y acaso morigerando su reflexión sobre la reinvención de una identidad personal, el autobiógrafo concluye en esta ocasión:

My Mexican self is not altogether gone, nor is my American self so prevalent as to erase everything else. In between the two stands my Jewishness, moderating the tension, becoming an arbitrator and perhaps a censor (Stavans 2001: 253).

Un libro inquietante, de un inmigrante que se ha instalado en la casa de al lado y que nos desafía a cambiar de lugar. 


\section{Las nuevas rutas del Judío Errante}

La novela Bosque quemado de Roberto Brodsky tiene la particularidad de establecer una asociación irremediable entre el exilio político y la errancia judía. Texto autobiográfico, con un cuerpo bifronte situado simultáneamente en medio de la vida y en los márgenes de la ficción, gira en torno a la figura de Moisés Brodsky, su padre, un médico comunista que debe partir en 1973 hacia el exilio, instalándose primero en Buenos Aires, para pronto huir de allí por la Guerra Sucia y vivir precariamente en Caracas y calcinarse en un poblado oriental de ese país, denominado Lechería, para volver finalmente a Santiago de Chile, luego de diez años de exilio, convertido en cadáver viviente. Morirá arrasado por el alzheimer en plena transición a la democracia durante los años 90, despojado de todos sus quereres y con la memoria en blanco.

Un Moisés que ha extraviado el camino; no es ésta, sin embargo, la historia del padre (nunca se nos habla desde su conciencia), sino la del hijo, aquel huérfano que lo sigue como guardián y emisario por esas cartografías migrantes, sirviendo de enlace afectivo y culposo con la familia y también con el proyecto utópico marxista, y convirtiéndose en el nuevo judío errante latinoamericano.

La novela se abre como en una sinfonía, con golpes en la puerta, como si el destino llamara al personaje a emprender nuevos derroteros. En el "nuevo Chile" de los años 90, Moisés toca la puerta del departamento de su hijo menor, el que lo ha seguido a todas sus peregrinaciones, para que lo acoja: "Mi padre dice soy yo, tu padre, ábreme" (Brodsky 2007: 15). Irónico nudo de la orfandad, un hijo en busca de amparo debe acoger al supuesto guía de la tribu. Son los nidos vacíos de una familia en tránsito, cuyo supuesto drama se inicia años antes del golpe militar, cuando la mujer de Moisés se instala a vivir con otro hombre, mucho menor que ella.

Exilio marxista, errancia judía, sujetos suspendidos en el aire o girando en redondo. El hijo -que jamás pronuncia su nombre, que anda a tientas por el mundo- le sigue los pasos al padre, para que no se extravíe, reeditando antiguas redes familiares -la parentela judía bonaerense- y a la vez él mismo agregando puntos de fuga a esta cartografía latinoamericana: se instala por un tiempo en Barcelona; pero de allí sale expulsado, volviendo entonces a Santiago, donde recién se ha 
reinstalado su padre. Desde el recuento de la escritura, escuchamos: "mi padre era mi país, mi patria portátil. Yo sería del lugar donde estuviese él" (Brodsky 2007: 70).

¿Cómo rescatar la figura debilitada del padre?, ¿cómo nombrarse a sí mismo? Desde el presente de la escritura, interpreta la vida de Moisés desde la tradición del pueblo elegido. La elección de la medicina como una disciplina sagrada, el abrazo del comunismo como un mandato mesiánico, su exilio como un círculo más de la espiral diaspórica, que en el ámbito familiar se inició con el viaje de la matriarca Ana Kotlowicz hace cien años desde la localidad de Dnepropetrovsk a una esquina perdida del mundo.

Ahora bien, la medicina y el comunismo constituyen también cartas de asimilación en los discursos de la nación moderna; pero que no logran atajar el descalabro del alzheimer, enfermedad que es explicada por el doctor con una metáfora escolar:

Imaginen que su cerebro fue víctima de un incendio que arrasó con recuerdos, referencias, memoria, todo [...] Un bosque quemado donde todavía quedan algunos árboles y ramas humeantes (Brodsky 2007: 124).

$\mathrm{Y}$ es aquí donde se desata otro ánimo judío: el miedo ancestral al daño, reeditándose una catástrofe, ahora a nivel simbólico: Lechería es sentida como una estación sin Dios, donde Moisés había comenzado a calcinarse figuradamente, culminando con la quema en la clínica y la conversión en cenizas.

Cuerpo ingrávido, una voz sin nombre propio enuncia su relato en un constante vaivén temporal: nos adelantamos y retrocedemos en un tiempo circular, suspendido en la incertidumbre. El hijo con su padre a cuestas es expulsado de los lugares de origen, con el agravante de que al volver a Santiago, corazón de lo natal, éste se ha convertido en un punto errático más: "Nada estaba en su lugar, y aquello parecía no tener fin" (Brodsky 2007: 27).

$\mathrm{Y}$ sin embargo, en todos estos recorridos se van recuperando alianzas, antiguas redes judías de parentesco que persisten a pesar de un sino destructivo. Así, cuando huyen de Chile en 1973 se refugian en casa de los tíos en Buenos Aires, y nuestro hijo, una vez pasada la pesadilla de las persecuciones y muertes en suelo argentino, vuelve nuevamente donde sus primos para la celebración del primer bar mitza 
desde la llegada de la matriarca Ana Kotlowicz a estos confines sudamericanos hace cien años.

Los lazos judíos como único suelo; la vivencia desplazada de las persecuciones durante la era nazi y la Shoá (cuerpos quemados, almas cenicientas), y el miedo del ser humano a transformarse en una memoria extinta: éstos son los derroteros de las letras migrantes chilenas. Al respecto, recordemos que en muchos testimonios judíos se recupera una impronta familiar desde una colección de imágenes sagradamente guardadas en la memoria, las cuales tienen sus referentes materiales en nimios objetos atesorados: manteles de granité, tacitas de porcelana blanca con una línea azul cobalto en el borde; o gestos y rutinas mantenidas en el hogar; amén de las historias contadas y transmitidas. Estoy pensando, por ejemplo, en los escritos de Marjorie Agosín, Sabina Berman y Sonia Guralnik. Pues bien, en el caso de la familia Brodsky, el alzheimer destruye ese cofre de ilusiones, instalando el desquiciamiento y la muerte como emblemas virtuales de la memoria. El hijo cae en cuenta de la enfermedad de su padre durante una visita a una exposición de arte moderno, cuando observa un cuadro que muestra a una madre casi sepultada por hallullas y marraquetas de pan, como bañándose en objetos nutricios primarios. Esa imagen le permite entender el orden instalado por su padre Moisés en el departamento donde él lo está acogiendo:

Me estremecí y el pavor me invadió. A mi mente acudieron relojes, paquetes, bolsas plásticas, ruidos de llaves, cucharas y tenedores abandonados en el baño junto a un arsenal de movimientos en falso que percutían sobre los muros como el cadáver del arte moderno azotado en el aire retenido del museo (Brodsky 2007: 87).

En breve, el resumidero, la desagregación que torna inútil y destruye el aura de las cosas.

Quien cuenta la historia familiar es un artista, alguien dedicado a la fotografía y a la escritura de relatos. Esta novela resulta así un registro de memoria; pero está concebido más como un borrador personal que como una crónica de familia: son señas de identidad, huellas de incertidumbre, ejercicios de entrada a un árbol genealógico milenario. Siendo fotógrafo, pareciera que la autoría también se resiste a la confección de un álbum, o más bien, lo que realiza es una serie de tomas sobre una misma persona, su padre Moisés, para animarlo, rescatarlo, reconocerlo, para fijarlo en la memoria. 
En esta novela se siente la nostalgia por el hogar, existiendo la voluntad irrevocable de reconstituirlo en el tiempo, aunque sea por fragmentos. El "desgüece familiar" (metáfora barroca ensayada por el biógrafo), producto de la separación matrimonial de los padres y del exilio político, no logra romper una alianza filial, familiar y comunitaria, que se retrotrae por cierto a la trascendencia del tronco judaico. Este gesto no anula, sin embargo, una incertidumbre y una inseguridad radicales que acompañan a este hijo de las diásporas latinoamericanas del último tercio del siglo $\mathrm{XX}$, y que se presenta ante nosotros absorto y ensimismado en el tiempo de la migrancia.

\section{Huerfanías}

Queremos ahora presentar a una escritora chilena cuya obra Poste restante se concibe desde viajes erráticos hacia un origen que siempre aparece desplazado en la serie de puntos recorridos en una cartografía que incluye, entre otras paradas, Tel Aviv, Jerusalén, Chipre y localidades de Ucrania y Polonia. Es una rebelde chilena que ensaya el viaje inverso de sus ancestros inmigrantes, visitando posibles lugares de origen, no para encontrar certidumbres, sino para constatar los blancos de la memoria, para dejarlos al desnudo y reeditar allí acaso un origen más antiguo, de decepción y desafecto.

Situación inicial. Cynthia Rimsky recorre un domingo un mercado persa en un barrio santiaguino, feria de cachivaches exhibida como rezago de nuestra memoria. Sin mayores datos sobre sus abuelos judíos inmigrantes de Ucrania y ante un persistente silencio familiar sobre imágenes del pasado, se encuentra con un álbum de fotos perteneciente a una familia de apellido idéntico al suyo, con la excepción de una letra. Se apropia de este álbum, fechado en 1940 en la localidad de Jezersko y decide emprender un viaje en busca del pasado de esos personajes y lugares remotos. Cynthia lo explica así: "Como no le interesaba encontrar parientes vivos o su nombre en una tumba, decidió que buscar un origen de las fotografías podía ser tan real como el otro" (Rimsky 2001: 11).

Un álbum como disparador de un viaje muchas veces postergado; un viaje diseñado como un ready-made, en el cual la sujeto es tanto la artista que programa el recorrido como la persona que lo emprende; un libro que es armado a su vuelta a Santiago al modo de una Instala- 
ción Plástica que incluye una serie de objetos que registran una experiencia, dispuestos en un texto móvil: allí, fotocopias de mapas, de cartas de sus amigos devueltas al remitente y sólo leídas a la vuelta, la agenda con datos de dinero y apuntes de direcciones, el cuaderno azul con borradores de relatos y las fotos del álbum.

Son las marcas de su paso por territorios constituidos desde la fractura y la sustitución. Los puntos elegidos constituyen lugares trastocados: por ejemplo, la frontera de Israel y Egipto; por ejemplo, Chipre, dividida artificialmente en dos (la viajera se instala en el sur, donde hay bases inglesas de ocupación). En su cuaderno de notas leemos lo siguiente: "Alektora era un villorrio turco que quedó en el sur. Ahora lo habitan refugiados griegos del norte. Viven aquí hace veinte años y siguen considerando que las casas pertenecen a los turcos" (Rimsky 2001: 58). Las traslaciones chipriotas riman con las sustituciones en tierras de Polonia. Aquí la población original aparece ocupada (invadida) por fuerzas militares extranjeras y por el idioma inglés. Y finalmente, acaso en el centro de este laberinto, aparecen los espacios vaciados, borrados o desocupados, como las aldeas judías de Cracovia.

Se va al encuentro de las incertezas, de la condición de orfandad del individuo y, también, al desentramado de una identidad individual. Los lugares transitados iluminan la fractura del sujeto contemporáneo, su falta de regazo. A estos espacios desencajados (donde significante y significado nunca coinciden) se les opone el espacio chileno, que reúne amigos, parientes, casas, barrios y paseos familiares; a pesar de que también se quiera escapar de él por la imposibilidad de construirse allí una vida como artista.

El libro se denomina Poste restante, aludiendo a la serie de cartas que la protagonista debiera reclamar en el correo de la respectiva ciudad que visita, pues sus amigos chilenos saben sólo el radio de acción de la destinataria, pero no su punto exacto de residencia. Lo cierto es que muchas cartas rebotan y son devueltas a su remitente, puesto que la viajera ha llegado justo antes o justo después al lugar de la cita. Cartas que son leídas con posterioridad, en otros tiempos, lugares y contextos; cuerpos errantes que miman el acto fallido de encontrar una casa, que juegan a hacerla aparecer y desaparecer, ficciones de la comunicación, simulaciones del acto del náufrago que lanza un mensaje dentro de una botella. Jugar a las despedidas y desencuentros, escenificar la ansiedad, actuar los saltos mortales del trapecio. 
Texto vanguardista que de paso exhibe una erótica letal, que transita por los equívocos de las relaciones sexuales y expone los tabúes que amenazan con constituir de otro modo los orígenes. Paradójicamente, un texto de raigambre afectivo nacional, pues tiene a Chile como origen y destino, conformando los demás puntos una constelación vacía (una mancha blanca) que no logra generar una trascendencia o un nuevo camino. Sólo está ahí como tejido roto, el cual a lo más sirve como pantalla para exhibir la crisis de la teología, la política, la familia y el amor. En realidad, son los paisajes del desencanto.

Ustedes preguntarán si esta viajera encuentra finalmente a la familia que aparece en el álbum. En realidad, llega al lugar, Jezersko (situado en la actual Eslovenia), donde hacia 1940 había unos baños termales, que constituyen el escenario de las fotos. Lo que ella creyó era un apellido -"Rimski" - significa en el idioma esloveno "baño romano", y "Rimsky Vrelec", los supuestos dos apellidos anotados en el álbum, "baños termales". Su nombre, un lugar por donde pasan las aguas; y su apellido transpuesto y traducido, "Bañados". Por cierto, nuestra mochilera llega hasta allí, y deja el álbum en manos de la familia que ha sido dueña de esas termas, ahora abandonadas. Regalo bien acogido, pues la mujer de la casa reconoce en una de las fotos la casa donde ella nació. Una emisaria que viene desde un remoto lugar suramericano dona una parte extraviada del puzle a una familia eslovena. De la familia de la foto, se supone que son veraneantes austríacos, seguramente pronazis. En el libro no aparecen las fotos del álbum sino sus descripciones. El reverso de la Historia, unos cuerpos sustituyendo a otros, ambos ausentados.

No se crea, sin embargo, que Cynthia no busca también a los suyos, ya sea su posible genealogía en el Museo de la Diáspora en Israel o alguna seña de su abuelo León Rimsky en su localidad natal, Ulanov. Sólo que constata que no hay rastros; lo cual pareciera que lo sabía desde el inicio del viaje. Lo novedoso consiste en que en el encuentro con estos paisajes y el diálogo casual con los lugareños, resurgen imágenes de infancia de los seres queridos en Santiago, de calles y casas también hoy abandonadas. Así, el viaje cobra también sus rizos nostálgicos. Ahora bien, nuestra autora, biógrafa de sí misma, que se presenta como la viajera, la chilena, la turista, la periodista que hace un reportaje, la escritora que hace una novela, la nieta de León Rimsky; eludirá todo discurso trascendente, sublimado o afectivo, 
resistiéndose siempre a un acunamiento total. Sujeta postmoderna, no le interesa ser colmada, ni menos integrada, sólo constituirse desde los intersticios, pues allí tiene más libertad de decisión, con el riesgo, y ella lo sabe, de ser una peregrina eterna.

En breve, a diferencia de otras voces judías, Rimsky no recrea sagrados vínculos, no rescata voces de los mayores, no refunda lugares de origen; por el contrario, constata su pérdida; lo cual sea acaso el modo más misterioso de un reclamo de posesión y de acogimiento que le ha sido negada a las nuevas generaciones. La instalación artística que resuelve este viaje es el espacio de orfandad que se nos invita a compartir para registrar los nuevos nudos de la memoria.

\section{Final}

Estos cuatro relatos nombran imágenes opuestas y complementarias del sujeto judío contemporáneo: retoños que nunca se alejan del hogar, rebeldes que vuelven a nacer en otras tierras e idiomas, migrantes que han perdido sus referentes, jóvenes privados de memoria; todos guiados por la misma pasión de convivir con el judaísmo, que está en el inicio y está en el fin.

\section{Bibliografía}

Brodsky, Roberto (2007): Bosque quemado. Santiago: Mondadori. Rimsky, Cynthia (2001): Poste restante. Santiago: Sudamericana. Sefamí, Jacobo (2004): Los dolientes. México, D.F.: Plaza y Janés. Stavans, Ilan (2001): On Borrowed Words. New York: Viking. 
